\title{
Temperature Influence On The Drawing Process Stability With The Reduction Of The WALl ThickNeSS
}

\author{
Himzo Đukić, Mirna Nožić \& Darko Šunjić
}
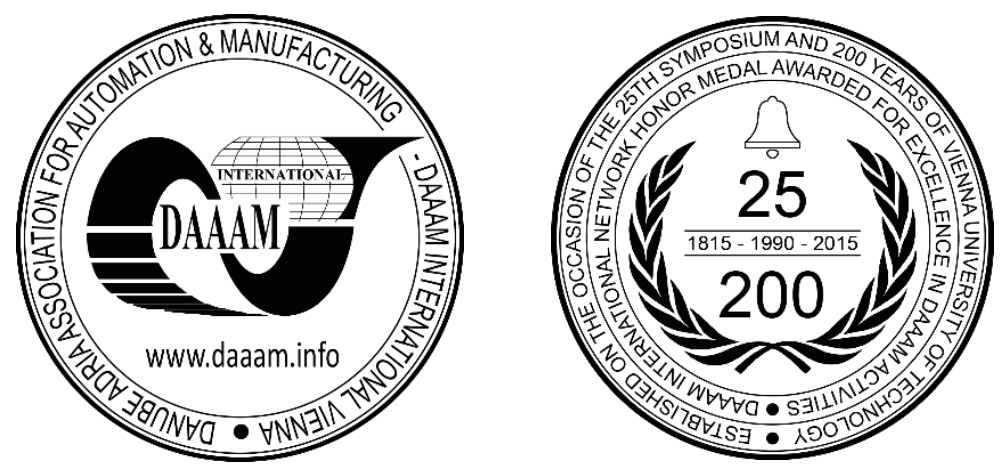

This Publication has to be referred as: Dukic, H[imzo]; Nozic, M[irna] \& Sunjic, D[arko] (2016). Temperature Influence on the Drawing Process Stability With the Reduction of the Wall Thickness, Proceedings of the 27th DAAAM International Symposium, pp.0708-0713, B. Katalinic (Ed.), Published by DAAAM International, ISBN 978-3-90273408-2, ISSN 1726-9679, Vienna, Austria

DOI: $10.2507 / 27$ th.daaam.proceedings.102

\begin{abstract}
The cold drawing process takes places very quickly and during the conversion of mechanical energy into the heat energy the work peace and the tool heat up considerably. In order to achieve a stabile drawing process, it is necessary to keep tracks of the temperature growth of the work piece and the tool. The tool temperature has to be below the established limits, and it is regulated by the amount of the coolant, which is at the same time also a lubricant. The expressions for the temperature growth calculation in the conditions of adiabatic processes that can also be applied to the deep drawing process with the reduction of the wall thickness, due to the high deformation rate, have been presented in the work. The heat balance equation enables the determination of the coolant mass which will maintain the stabile tool temperature, what is confirmed by the experimental researches.
\end{abstract}

Keywords: Drawing with the reduction of wall thickness; heat balance; tool temperature.

\section{Introduction}

Deep drawing is the forming of smooth (sheet) blanks into hollow parts. It is a process which involves forming by tensile and compressive forces. [1]. Deep drawing process has to be surely considered as fully assessed since it was developed in the 1700s. Starting from that date, the process was extensively studied and it has become a strategic process in metalworking field [2]. Different cylindrical elements on the multi-tools are being made by the deep drawing process with the reduction of the wall thickness.

This process happens during mass production by the continuous passing of the work piece through several rings set one behind the other in the tool. The presentation of the process indicates a complex deformation mechanism, where during the passing of the work piece through the tool, the reduction of the wall at the diameter and the wall thickness occurs at the same time, as shown in Fig. 1 (a. 2D presentation, b. 3D presentation). 


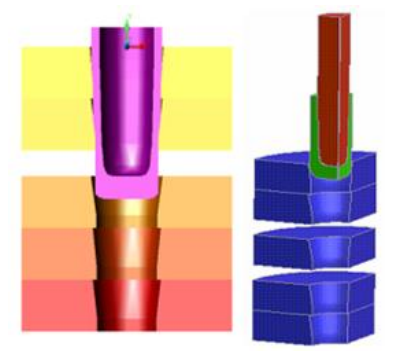

Fig. 1. Scheme of drawing on the multi-tools

When projecting a technological process of the deep drawing with the reduction of the wall thickness, special attention should be paid to the heat effect that has a significant role in the processes of cold deformation. In order to achieve a stabile drawing process, it is necessary to keep tracks of the temperature growth during the process and control it, i.e. to control the heating of the tool [3].

\section{The heat effect during the deformation process}

In order to keep tracks of the energy conversion during the deformation process it is needed to define the thermodynamic system. Since all the deformation process happens at high deformation rate, for the purpose of problem elaboration, this process can be observed as an idealized case within the closed system, isolated in relation to the environment. This means that the process takes place at approximately adiabatic conditions.

The expression for the temperature growth calculation during the drawing at high speed (for the conditions of the adiabatic process) has been given as following [4]:

$$
\Delta t=\frac{\alpha \cdot x_{1} \cdot F_{1} \cdot h_{1} \cdot 10^{7}}{V_{0} \cdot \gamma \cdot c \cdot 4,184 \cdot 427}
$$

Where:

$F_{1}=d_{1} \cdot \pi \cdot s \cdot k_{1}[N]$ is the drawing force;

$V_{0}\left[\mathrm{~mm}^{3}\right]$ is the work piece volume;

$h_{1} \approx \frac{D_{0}{ }^{2}-d_{1}{ }^{2}}{4 d_{1}}$ is the drawing depth $[\mathrm{mm}]$;

$\alpha=0,85 \div 0,90$ is the coefficient

$x_{1}=0,70 \div 0,85$ is the diagram fullness coefficient $(\mathrm{F}, \mathrm{h})$;

$\gamma$ is the specific weight $\left[\mathrm{kg} / \mathrm{dm}^{3}\right]$ and

$\mathrm{c}$ is the specific heat $[\mathrm{J} / \mathrm{kgK}]$.

When reducing this expression (1), we obtain the following expression for the calculation of temperature growth during the deep drawing process:

$$
\Delta t=\frac{\alpha \cdot x_{1} \cdot \sigma_{1} \cdot 10^{7}}{\gamma \cdot c \cdot 427 \cdot 4,184}
$$

where:

$\sigma_{1}\left[N / \mathrm{mm}^{2}\right]$ represents the drawing voltage.

After including the recommended values for the heat transfer coefficient $-\alpha=0,85$ and the diagram fullness coefficient we obtain:

$$
\Delta t=\frac{3806 \cdot \sigma_{1}}{\gamma \cdot c}
$$


where:

$\sigma_{1}=\varphi_{1} \cdot \sigma_{m}\left(\frac{1}{m_{1}}-1\right)$ is the deep drawing voltage.

for the relation $\frac{D_{0}}{s_{0}} \times 100=100 \div 200 \Rightarrow \varphi_{1} \approx 1,6$

For the deep drawing process with the reduction of the wall thickness, the specific deformation stress of the shape change is calculated by the expression:

$a_{1}=k_{1} \cdot \varphi_{1}$

where:

$k_{1}$ - specific deformation resistance of the material for the determined deformation stress in and

$\left[N / \mathrm{mm}^{2}\right]$ - value of logarithmic deformation.

$\varphi_{1}$ - value of logarithmic deformation.

Bearing in mind the (4), after the drawing process with the reduction of the wall thickness the temperature value is:

$$
t=t_{0}+\Delta t=20^{\circ}+\frac{3806 \cdot k_{1} \cdot \varphi_{1}}{\gamma \cdot c}
$$

When it comes to deep drawing process without the reduction of the wall thickness, the calculation of temperature after the process is obtained by the following expression:

$$
t=t_{0}+\Delta t=20^{\circ}+\frac{3806 \cdot \sigma_{m} \cdot\left(\frac{1}{m_{1}}-1\right)}{\gamma \cdot c}
$$

Where $\mathrm{m}_{1}$ stands for the drawing relation in the first operation.

Calculated temperature values according to the expression (6) for the deep drawing process without the reduction of the wall thickness for different materials have been given in the Table 1.

\begin{tabular}{|l|c|c|c|c|}
\hline \multirow{2}{*}{\multicolumn{1}{|c|}{ Material }} & \multicolumn{4}{|c|}{ Value of the drawing relation in the first operation } \\
\cline { 2 - 5 } & 0,6 & 0,55 & 0,50 & 0,45 \\
\hline Low carbon steel & 60 & 69 & 80 & 93 \\
\hline Stainless steel & 94 & 112 & 132 & 156 \\
\hline Aluminium & 38 & 42 & 47 & 53 \\
\hline Duralumin & 65 & 76 & 88 & 103 \\
\hline
\end{tabular}

Table 1. Calculated temperatures during the cold drawing process (adiabatic process)

\section{Determining the energy of the intermediate form during the deformation process}

The heat being released during the process causes the temperature growth of the work piece, which results in the reduction of its hardness, as well as in the reduced deformation resistance. The deformation process takes place at high deformation rates, leading to the softening of the workpiece material and increasing of its plasticity, as well as the reduction of the energy needed for deformation. According to the [5] during the deformation process around $80-90 \%$ of mechanic energy spent for the deformation process is released in the metal in terms of heat, wheras the rest of $20-10$ $\%$ remains in the metal in the form of residual stress. At higher deformation rates, the heat loss released in form of radiation to the environment is negligible. The energy conversion can be tracked if defining the thermo-dynamic system. Every thermo-dynamic system or his elements are characterized by a certain energy state. If we adopt the following as the system elements: the puller, work pieces, drawing rings and coolant, and if we adopt the supposition that the drawing process is seen as an idealized case within a closed system, isolated in relation to the environment it is possible to research, theoretically and experimentally, the energy of intermediate form and to determine the amount of heat and deformation stress during the deep drawing process with the reduction of the wall thickness. Exchanged amount of heat during the 
process from the initial state „1“ (before drawing) to the final state „2“ for the observed thermo-dynamic system is calculated according to the following expression [6]:

$$
\begin{aligned}
Q_{1,2} & =m_{i} \cdot c_{i} \cdot\left(T_{i 2}-T_{i 1}\right)+N_{i} \cdot m \cdot c \cdot\left(T_{2}-T_{1}\right)+ \\
& +m_{p} \cdot c_{p} \cdot\left(T_{p 2}-T_{p 1}\right)+m_{r s} \cdot c_{r s} \cdot\left(T_{r s 2}-T_{r s 1}\right)
\end{aligned}
$$

where:

$\mathrm{m}_{\mathrm{i}}$ is the puller mass,

$\mathrm{c}_{\mathrm{i}}$ is the specific heat of the puller's material for

Tref=1/2(Ti1+Ti2),

$\mathrm{T}_{\mathrm{i} 1}$ is the puller's temperature in the state 1 ,

$\mathrm{T}_{\mathrm{i} 2}$ is the puller's temperature in the state 2 ,

$\mathrm{N}_{\mathrm{i}}$ is number of work pieces drawn from the state 1

to state 2 ,

$\mathrm{m}$ is the mass of the work pieces,

c is the specific heat of the work piece material

for Tref $=1 / 2$ (To1+To2),

$\mathrm{T}_{1}$ is the temperature of the work pieces in the state 1 ,
$\mathrm{T}_{2}$ is the temperature of the work pieces in the state 2 ,

$\mathrm{m}_{\mathrm{p}}$ is the mass of the drawing rings,

$c_{p}$ is the specific heat of the ring materials for

Tref $=1 / 2(\mathrm{Tp} 1+\mathrm{Tp} 2)$,

$\mathrm{T}_{\mathrm{p} 1}$ is the rings temperature in the state 1 ,

$\mathrm{T}_{\mathrm{p} 2}$ is the rings temperature in the state 2 ,

$\mathrm{m}_{\mathrm{rs}}$ is the coolant mass,

$\mathrm{c}_{\mathrm{rs}}$ is the specific heat of the coolant for

Tref $=1 / 2(\operatorname{Trs} 1+\operatorname{Trs} 2)$,

$\mathrm{T}_{\mathrm{rs} 1}$ is the temperature of the coolant in the state 1 ,

$\mathrm{T}_{\mathrm{rs} 2}$ is the temperature of the coolant in the state 2 .

Mechanical work (W) is another form of intermediate energy and it can be defined as a scale product of the force vector and the motion vector. If $\mathrm{Fl}=\mathrm{Fl}(\mathrm{l})$, the mechanic work is calculated according to the following:

$$
W_{1,2}=\int_{1}^{2} \vec{F}(l) d \vec{l}=\int_{1}^{2} F(l) \cos \varphi d l=\int_{1}^{2} F_{l}(l) d l \quad[J]
$$

In order to determine the deformation stress during the drawing process, we need to integrate the diagrams of the dependence of the deformation force on the drawing path and to multiply the given value with the number of the drawn work pieces between the referential states ,1" and ,2".

By comparing the heat value $\left(\mathrm{Q}_{1,2}\right)$ and the deformation stress $\left(\mathrm{W}_{1,2}\right)$ we get the answer on the percentual relation of the energy released for heat and the one spent during the deformation process.

The expression (7) enables the calculation of the needed amount of the coolant during the drawing process [7]:

$$
m_{r s}=\frac{Q_{12}-m_{i} c_{i}\left(T_{i 2}-T_{i 1}\right)-N_{i} m c\left(T_{2}-T_{1}\right)-m_{p} c_{p}\left(T_{p 2}-T_{p 1}\right)}{c_{r s}\left(T_{r s 2}-T_{r s 1}\right)}
$$

By determing quantity of the revised heat and work of plastic deformation in deep drawing process with reduction of wall thickness it is possible to determine the amount of coolant necessary to ensure a stable drawing process.

\section{Results of the experimental research of the intermediate form of energy during the drawing process}

In order to determine the amount of energy released in the form of heat during the process of deep drawing with the reduction of the wall thickness, by an experimental research, it is necessary to measure and register the deformation force and to measure the temperature of all the system elements before and after the drawing process. The deformation force is determined by the usage of the tensometer device „Spider 8 “ with the appropriate software. Measuring chain sketch for registration of drawing force on multi-stage tools in given in Fig. 2.

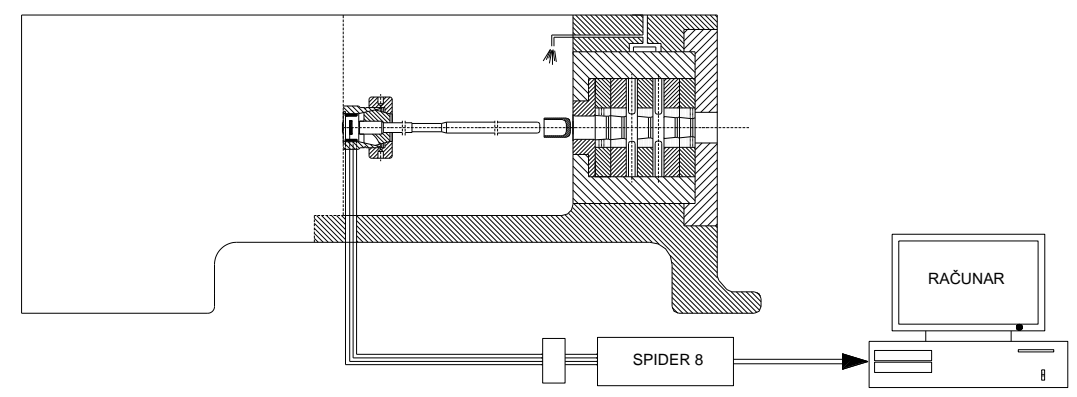

Fig. 2. Sketch of measuring chain in production condition 
Using a measuring chain were obtained addiction diagrams of deformation force and draw stroke. Typical diagram from one measurement is given in Fig. 3.

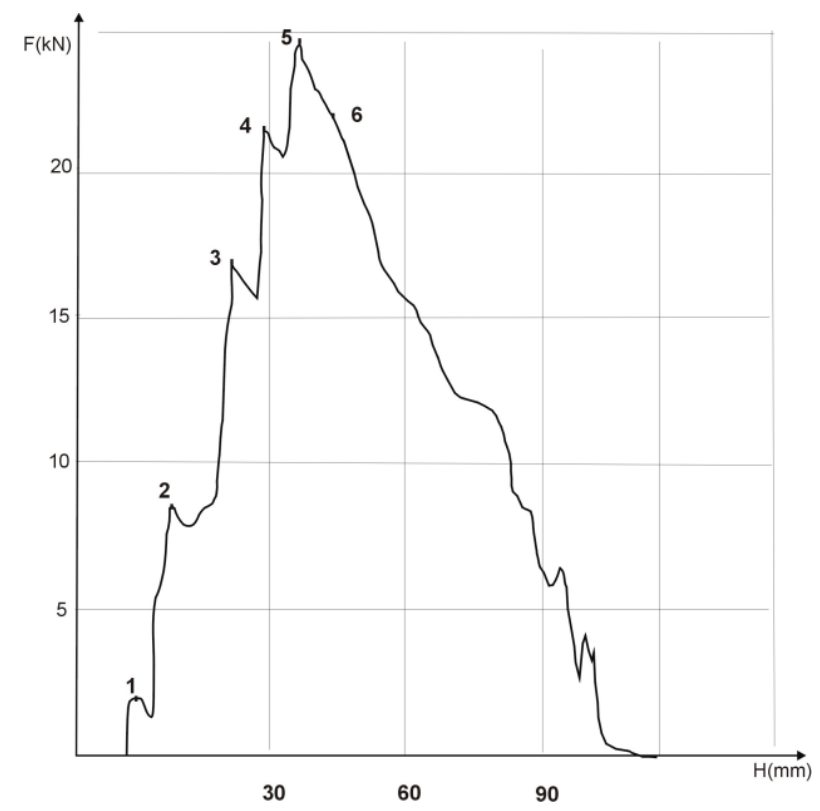

Fig. 3. Diagram of drawing force on multi-stage tool

By integrating the diagram of the dependence of the deformation force on the drawing path we obtain the value of the deformation stress or the energy spent on deformation. Registering of the temperatures before and after the drawing was done with laser measuring device and with thermography. Temperature measurement results before and after drawing are given in Table 2.

\begin{tabular}{|c|c|c|c|c|c|c|}
\hline \multicolumn{7}{|c|}{ System elements temperature values before drawing } \\
\hline \multirow{2}{*}{ No. } & \multicolumn{2}{|c|}{$\begin{array}{c}\text { Puller temperature } \\
T_{i l}\left({ }^{\circ} \mathrm{C}\right)\end{array}$} & $\begin{array}{c}\text { Blank } \\
\text { Measuring spots }\end{array}$ & $\begin{array}{c}\text { Rings } \\
\text { temperature } \\
T_{l}\left({ }^{\circ} \mathrm{C}\right)\end{array}$ & $\begin{array}{c}\text { temperature } \\
T_{p 1}\left({ }^{\circ} \mathrm{C}\right)\end{array}$ & $\begin{array}{c}\text { Coolant } \\
\text { temperature } \\
T_{r s}\left({ }^{\circ} \mathrm{C}\right)\end{array}$ \\
\cline { 2 - 4 } & 1 & 2 & 3 & 22 & 21 & 29 \\
\hline 1 & 20 & 21 & 21 & 22 & 21 & 33 \\
\hline 2 & 22 & 22 & 22 & 22 & 21 & 33 \\
\hline 3 & 22 & 21 & 22 & 22 & 29 & 35 \\
\hline \multicolumn{7}{|c|}{ System elements temperature values after drawing } \\
\hline 1 & 40 & 35 & 34 & 39 & 30 & 35 \\
\hline 2 & 40 & 35 & 34 & 40 & 30 & 36 \\
\hline 3 & 40 & 39 & 35 & 39 & 30 & \\
\hline
\end{tabular}

Table 2. System elements temperature values before and after drawing

Thermography of temperature fields on blanks and on drawing rings is given in Fig. 4.

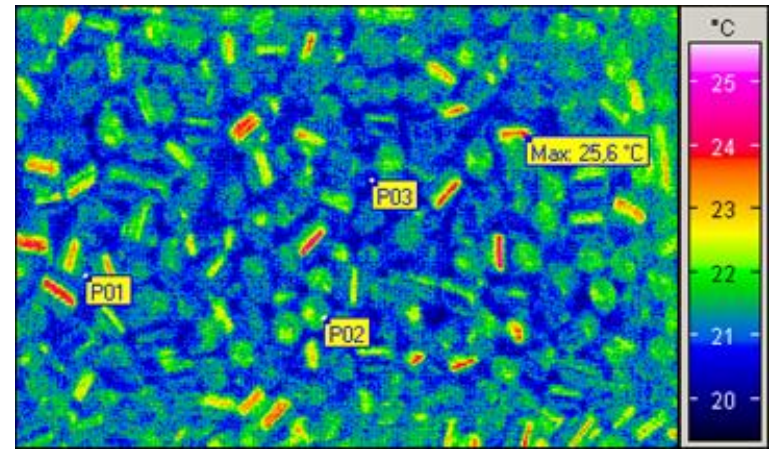

$\mathrm{Pmax}=25,6^{\circ} \mathrm{C}, \mathrm{P} 01=20,8^{\circ} \mathrm{C}, \mathrm{P} 02=21,7^{\circ} \mathrm{C}, \mathrm{P} 03=19,8^{\circ} \mathrm{C}$

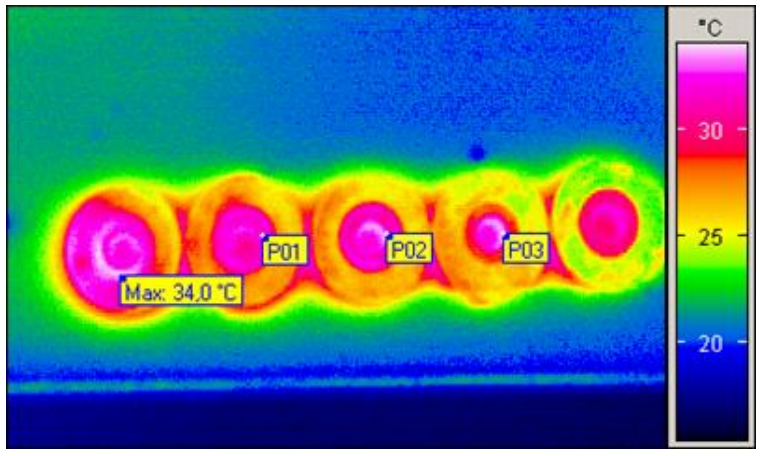

$\operatorname{Pmax}=34,0^{\circ} \mathrm{C}, \mathrm{P} 01=30,1^{\circ} \mathrm{C}, \mathrm{P} 02=30,6^{\circ} \mathrm{C}, \mathrm{P} 03=30,8^{\circ} \mathrm{C}$

Fig. 4. Temperature fields on blanks and drawing rings 
For the calculation of the exchanged heat amount between the two reference states of the observed system, the average values of the registered temperatures of the system elements, their masses and specific heats were used [8]:

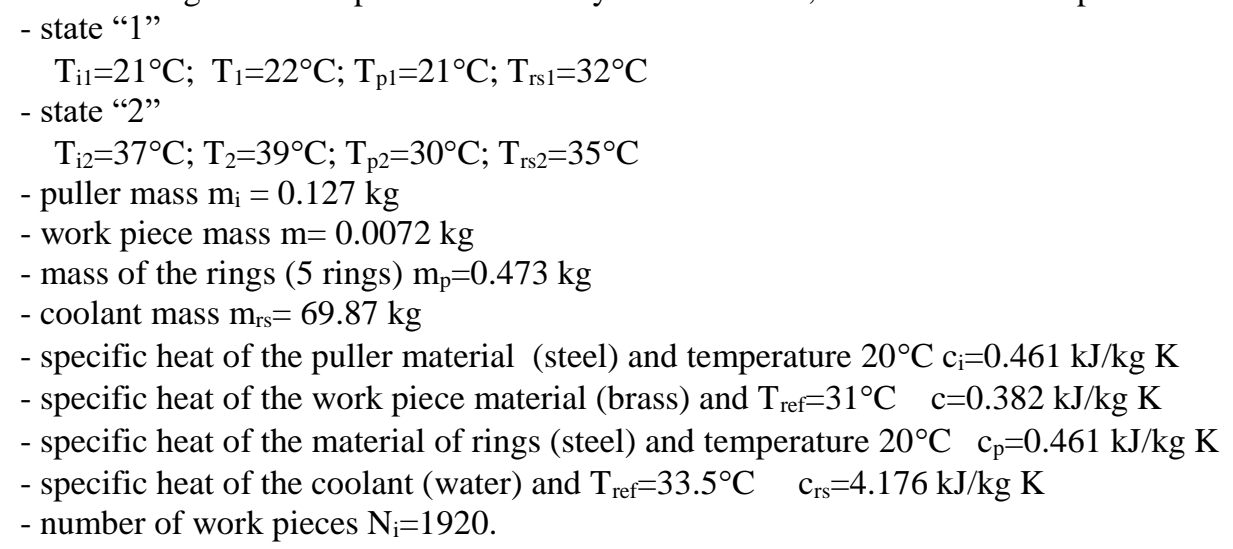

Specific heat values of the puller materials and rings (steel) have been adopted as for the temperature of $20^{\circ} \mathrm{C}$, due to the fact that charts on heats do not contain values for reference temperatures. By implementing the listed data into the expression (7), we get the value of the exchanged amount of heat for the observed system from state " 1 " to state " 2 " $\mathrm{Q}_{1,2}=967.79 \mathrm{~kJ}$

The value of deformation stress $\mathrm{W}_{1,2}$ is obtained when multiplying the deformation stress for one work piece $(\mathrm{W}=0.638$ $\mathrm{kNm}=0.638 \mathrm{~kJ}$ ) with the amount of the drawn work pieces $\mathrm{N}_{\mathrm{i}}=1920$. The obtained value of the deformation stress is $\mathrm{W}_{1,2}=1224.96 \mathrm{~kJ}$.

Measuring of the tool temperatures after the drawing process has shown that the puller has a slightly higher temperature $\left(\mathrm{T}_{\mathrm{i} 2}=37^{\circ} \mathrm{C}\right)$, and the temperature of the drawing rings is slightly lower $\left(\mathrm{T}_{\mathrm{p} 2}=30^{\circ} \mathrm{C}\right)$.

The expression (8) enables the determination of the coolant mass that allows a stabile drawing process. If the maximal temperature of the tool is restricted to $\mathrm{T}=40^{\circ} \mathrm{C}$, in order to have a stabile drawing process, then it is, according to the expression (8), necessary to ensure that there is an amount of the coolant $\mathrm{m}_{\mathrm{rs}}=69,67 \mathrm{~kg}$ circulating during the process.

\section{Conclusion}

Stability of drawing process with a reduction of wall thickness in production conditions at high speeds of drawing essentially depends on the correct certain amount of coolant and lubricant. In order to solve this problem experimental research of the energy transition forms (exchanged heat and work of plastic deformation) in the process of drawing with a reduction of wall thickness was done.

By recording drawing force on 1920 workpieces and simultaneous registration of the temperature on: workpieces, punch, puller, drawing rings and coolant, the results obtained, which allows calculation of mass of coolant that is required to calculate mass of coolant that which is required to limit the maximum temperature to $\mathrm{T}=40{ }^{\circ} \mathrm{C}$.

The calculated temperature value of the theoretical expression (6) in the drawing without reduction of the wall thickness, are shown in Table 1, indicate that in different materials occur high temperatures, which could impair the stability of the drawing process if the amount of coolant is not correctly determined.

Further researches should be expanded to other metal forming processes by deforming the blanks from various materials.

\section{References}

[1] Tschaetsch, Heinz: Metal Forming Practise Processes - Machines - Tools, Springer-Verlag Berlin Heidelberg, 2006. ISBN 978-3-540-33217-6

[2] G. Ambrogioa, L. Filice, G. Palumbo, S. Pinto: Prediction of formability extension in deep drawing when superimposing a thermal gradient, Journal of Materials Processing Technology 162-163 (2005) 454-460

[3] Đukić H., Nožić M. :,, Metal forming“, Univerzitet „Džemal Bijedić“ Mašinski fakultet Mostar, Mostar 2013

[4] L.A.Šofman :,, Theory and cold processes “, Mašinostroenie, Moskva, 1964

[5] Čaušević, M.: „, Metal plastic deformation”, Svjetlost Sarajevo, 1979

[6] Nožić M., Đukić H. :, Heat effect in the process of deep drawing with high speed “, MATRIB $\square 12$ International Conference MATERIALS,TRIBOLOGY, RECYCLING, 2012, Vela Luka, Croatia

[7] M.Nožić, H.Đukić, D.Denjo: „, Heat balance of drawing processes with a reduction of the wall thickness “, COMETa 2014, 2nd International Scientific Conference, decembar 2014, Jahorina, BiH

[8] Nožić, M. :, Contribution to the study of individual and total loads on multistage tools for drawing with reduction of wall thickness", Doktorska disertacija, Mašinski fakultet, 2005 